\title{
Gas Release Characteristics in Coal under Different Stresses and Their Impact on Outbursts
}

\author{
Hanpeng Wang ${ }^{1, *}$, Bing Zhang ${ }^{1, *} \mathbb{C}$, Liang Yuan ${ }^{2}$, Guofeng $\mathrm{Yu}^{3}$ and Wei Wang ${ }^{1}$ \\ 1 Research Centre of Geotechnical and Structural Engineering, Shandong University, Jinan 250061, China; \\ 201714565@mail.sdu.edu.cn \\ 2 School of Mining and Safety Engineering, Anhui University of Science and Technology, \\ Huainan 232001, China; yuanl_1960@sina.com \\ 3 Ping'an Coal Mine Gas Control National Engineering Research Center Co., Ltd., Huainan 232002, China; \\ 201613400@mail.sdu.edu.cn \\ * Correspondence: whp@sdu.edu.cn (H.W.); zhangbsdu@163.com (B.Z.); Tel.: +86-531-88399182 (H.W. \& B.Z.)
}

Received: 3 September 2018; Accepted: 2 October 2018; Published: 5 October 2018

\begin{abstract}
The impact mechanism of in situ stress on outbursts plays a key role in the prevention of outbursts during deep coal mining. The in situ stress may influence the outburst by affecting the gas release intensity according to theoretical analysis, but none of the existing studies have taken into consideration this perspective. To explore whether the influence of in situ stress on gas release in coal is an important reason for stress-induced outbursts, experiments on gas release in coal under different axial stresses and on exposure-induced outbursts with different gases were conducted to respectively study the influence of in situ stress on gas release and the impact of gas release on outburst. The results show that with the increase of stress, the methane release intensity rises by 1 2.4 times and shows an obvious periodicity due to different degrees of fracture development. A small increase in gas release intensity can lead to huge increase in the outburst intensity based on an energy analysis of the outburst experiments, indicating that the gas release intensity is a sensitive physical quantity that influences outbursts. The differences in gas release in coal with different stresses will result in differences in the outburst results based on data from the two experiments, proving that the change in gas release intensity during variations of in situ stress is an important factor for in situ stress-induced outbursts. The research achievements can enrich the impact mechanism of in situ stress on outbursts.
\end{abstract}

Keywords: coal and gas outburst; in situ stress; gas release; impact mechanism

\section{Introduction}

Coal and gas outburst is known as a destructive dynamic disaster in coal mines, which seriously restricts coal production safety [1,2]. Among various existing hypotheses on outbursts, the combined effect hypothesis has been widely recognized, which considers that coal and gas outburst is the result of the combined action of in situ stress, gas pressure, and the mechanical properties of coal [3-5], wherein the in situ stress plays a leading role in the emergence and development of outbursts [6].

During coal mining, mining disturbances damage the original balance of stress around the mine gob area, leading to stress redistribution in the mine shaft and around the stope, forming the "three zones" consisting of the pressure relief zone, the stress concentration zone, and the original stress zone in front of the excavation surface, which means that the coal rock in different mining phases is under different stress conditions $[7,8]$. In addition, dynamic disturbances such as blasting and drilling can also break the original balance of stress to change the coal stress state $[1,9]$. The changeable in situ stress increases the occurrence of outbursts obviously [10]. Therefore, a study of the in situ stress mechanism on outbursts is urgently needed. 
The existing research indicates that increased in situ stress increases the risk of outbursts and the in situ stress level, direction, and main stress intensity were proven to be the key factors influencing the outburst risk [11-15]. To clarify the impact mechanism of in situ stress on coal and gas outbursts, many research works have been conducted. An established numerical model to analyze the outburst danger from the perspective of stress conditions observed that an increase of tectonic stress could enhance the potential energy accumulation ratio, meaning larger outburst tendency [16]. Gao carried out laboratory model tests and numerical calculations to simulate the process of soft coal uncovering by cross-cut, and found that the elastic potential energy is accumulated in coal because of the stress concentration, which is the energy preparation and inoculation for outburst [17]. Liu established a coupled model and applied it into COMSOL numerical software; he found that the elastic potential energy of the coal continuously accumulates and the effects of stress gradually intensify, and believed that an outburst is likely to occur when the energy exceeds the surface energy of the coal body at the "Key point" [18]. Nie illustrated the mechanism of coal and gas outburst induced by vibration through examples: vibration would increase gas gradient and fractures in the internal coal body, which aggravates the risk of coal and gas outburst greatly [1]. Cheng investigated the controlling effect of ground stress on outburst disaster based on theoretical analysis and field verification, and obtained that the tectonic stress may lead to high gas pressure and low strength of the tectonic coal [19]. Based on the actual experience in the Pingdingshan coalfield, $[20,21]$ found that highly sheared and fractured coals likely act as a prerequisite for outbursts, because intense shearing will further lower the strength of coals and increase storage of methane. Jasinge conducted studies on gas permeability in brown coal at different confining pressures, and the test results depicted an exponential reduction of coal permeability when effective stress increases, which will affect the migration and storage of coal gas [22]. Based on existing studies, the impact mechanism can be summarized as follows: (1) High in situ stress facilitates the accumulation of elastic potential energy in the coal, providing an energy basis for the emergence and development of an outburst; (2) high in situ stress destroys the coal structure, reduces coal intensity, and the outburst energy threshold; (3) For the special case of shear coal, in situ stress changes its fracture connectivity and reduces its permeability, causing the difficulty of released gas flowing out of this local area in a short time and finally the increase of the coal gas pressure gradient.

The understanding of the impact mechanism of in situ stress on outbursts is constantly being enriched with existing studies, but it has yet to be comprehensive. According to theoretical analysis, the released gas may vary for coal under different stresses [23-25], which could exert an influence on the outburst risk due to its potential energy contribution in the outburst [26-28]. In other words, the in situ stress may influence the outburst by affecting the intensity of the gas release. However, none of the existing studies have taken into consideration this perspective.

In order to explore whether the influence of in situ stress on gas release in coal is an important reason for a stress-induced outburst, the influence of in situ stress on gas release intensity and its influence on the outburst were studied by laboratory experiments. Subsequently, the impact mechanism of in situ stress on outbursts was discussed from the perspective of gas release based on the experimental data.

\section{Experimental Devices and Procedures}

The experiment consisted of two parts. The first part entailed the experiments on gas release in coal under different axial stresses aimed at exploring and quantifying the change of gas release amount caused by in situ stress variations. The second part was the exposure-induced outburst experiments on different gases with different release intensities, with the purpose of examining the impact of gas release intensity on outburst. 


\subsection{Experiment on Gas Release in Coal}

\subsubsection{Experiment Apparatus and Working Principle}

The experiments on gas release in coal were conducted with an independently developed "gas release characteristic meter". As shown in Figure 1, the reference tank, sample tank, and gauge tank made of 304 stainless steel with a pressure resistance of $10.0 \mathrm{MPa}$, were where the gas adsorption and release occurred. Pressure sensors were installed on the tops of the three tanks to measure the pressure inside the tanks, and the pressure inside the gauge tank could be used for the calculation of gas release. A constant temperature water bath was used to control the experiment temperature ranging from room temperature to $100{ }^{\circ} \mathrm{C}$ with an accuracy of $\pm 0.1^{\circ} \mathrm{C}$. A vacuum pump pumped the instrument to $-0.098 \mathrm{MPa}$ to eliminate the interference of impurity gas in the instrument pipeline and experimental coal samples.

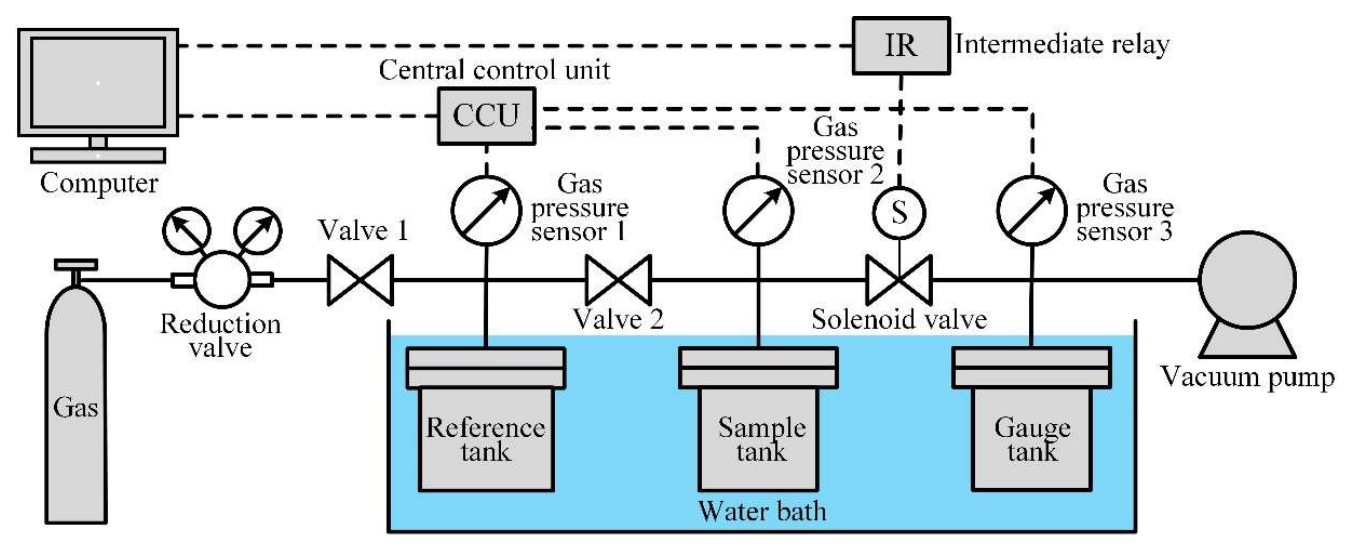

Figure 1. Meter for the gas release characteristics.

During the experiment, the gas in the sample tank and gauge tank contained the coal-released gas and the original free gas. Therefore, the mole number of the released gas could be calculated by subtracting the mole number of the free gas in the tank from the total mole number of gas in the tank. It can be expressed as follows:

$$
n_{\text {des }}=n_{\text {tot }}-n_{\text {ori }}
$$

where $n_{\text {des }}$ is the mole number of the released gas, $n_{\text {ori }}$ is the mole number of the free gas in the tank, $n_{\text {tot }}$ is the total mole number of the gas in the sample tank and gauge tank, which can be obtained from the real-time gas pressure in the tank by using the gas state equation, expressed as follows:

$$
n_{t o t}=\frac{p_{s c 1} V_{s c}^{v o i d}}{Z_{1} R T_{w b}}+\frac{p_{m c} V_{m c}}{Z_{2} R T_{w b}}
$$

where $V_{s c}^{\text {void }}$ is the volume of the void space in the sample tank which can be calculated by using the weight and true density of the coal sample, $V_{m c}$ is the space volume of the gauge tank, and $p_{s c 1}$ and $p_{m c}$ are the real-time pressure of the sample tank and the gauge tank during the process of gas release. $R$ is the molar gas constant, $T_{w t}$ is the water bath temperature; and $Z_{1}$ and $Z_{2}$ are the gas compression factors under $p_{s c 1}, p_{m c}$ and $T_{w t}$.

During the experiment, the gauge tank needed to be vacuumed, so the original free gas number $n_{\text {ori }}$ in the tank could be calculated by the free space volume and gas pressure of the sample tank. It can be expressed as follows:

$$
n_{\text {ori }}=\frac{p_{s c 2} V_{s c}^{v o i d}}{Z_{3} R T_{w t}}
$$

where $p_{s c 2}$ is the adsorption balance pressure of the coal sample, and $Z_{3}$ is the gas compression factor under $p_{s c 2}$ and $T_{w t}$. 
In order to facilitate the comparative analysis, the released gas volume per mass coal $V_{S T P}$ des under a standard temperature and pressure (STP) was obtained by using the mole number of the released gas, expressed as follows:

$$
V_{S T P}^{d e s}=\frac{n_{\text {des }} R T_{S T P}}{p_{S T P}\left(1-M_{a d}-A_{a d}\right) M_{c o a l}},
$$

where $p_{S T P}$ and $T_{S T P}$ are the pressure and temperature under standard conditions; and $M_{\text {coal }}$ is the mass of coal samples.

\subsubsection{Experiment Method and Procedure}

The basic idea of the gas release experiment was the following: Different axial forces were applied to the coal sample of $\phi 50 \times 100 \mathrm{~mm}$ to characterize different stress states of the coal, and then the stress-damaged coal sample was put into the sample tank for the gas release experiment. The pre-peak axial force of the coal sample was set at $0,2,4,6,8,10,12 \mathrm{MPa}$ (peak intensity), respectively, according to the measured coal stress-strain curve, and the post-peak axial force was set according to the actual loading situation due to the difficulty in controlling the post-peak loading state of brittle coal accurately.

To ensure the consistency with the actual working conditions, the experiment was performed with $99.99 \%$ methane which is the main gas in an outburst. In order to ensure the uniformity of the coal samples, the coal samples with obvious joints were screened out, and those with a wave velocity of $4000 \sim 4400 \mathrm{~m} / \mathrm{s}$ were selected before the gas release experiment. The coal samples used in the experiment were collected from the $C_{13}$ coal seam of Wangfenggang Coal Mining in the Huainan Mining Area, Anhui Province. The coal seam is characterized by coal and gas outbursts, where many coal and gas outburst accidents and prolonged outburst accidents have occurred. The type of the $C_{13}$ coal is fat coal. The results of proximate analysis are as follows: Apparent density $=1.40 \mathrm{~g} / \mathrm{cm}^{3}$, porosity $=3.45 \%$, moisture content $M_{a d}=1.04 \%$, ash content $A_{a d}=21.05 \%$, and volatile matter content $V_{a d}=24.26 \%$. Maximum vitrinite reflectance $R_{o, \max }=0.85 \%$. The results of petrographic analysis are as follows: Vitrinite $=83.3 \%$, inertinite $=15.7 \%$, exinite $=0.9 \%$. The pore volume distribution measured by mercury intrusion porosimetry (MIP) is as follows: macropore volume $(>1000 \mathrm{~nm})=43 \times 10^{-4} \mathrm{~mL} / \mathrm{g}$, mesopore volume $(1000 \sim 100 \mathrm{~nm})=17 \times 10^{-4} \mathrm{~mL} / \mathrm{g}$, transition pore volume $(100 \sim 10 \mathrm{~nm})=133 \times 10^{-4} \mathrm{~mL} / \mathrm{g}$, micropore volume $(<10 \mathrm{~nm})=114 \times 10^{-4} \mathrm{~mL} / \mathrm{g}$.

The coal was loaded by displacement control at a speed of $0.001 \mathrm{~mm} / \mathrm{s}$. According to the actual temperature of the mine, the gas release experiment was carried out at a constant temperature of $303 \mathrm{~K}$ which is consistent with the previous gas release experiment [29]. According to the gas reservation condition of the coal seam, the adsorption balance pressure of the coal sample was determined to be $0.75 \mathrm{MPa}$ (relative pressure). The measuring time was determined to be $10 \mathrm{~s}$ according to the outburst duration which ranged from a few seconds to more than ten seconds.

The specific experimental process was as follows:

(1) Airtightness testing: The airtightness of the instrument was checked with $6.0 \mathrm{MPa} \mathrm{N}_{2}$ before each set of measurements. When the pressure was kept stable for $24 \mathrm{~h}$, the airtightness was considered to meet the requirements.

(2) Placement and degassing of the coal sample: In the coal sample placement process, degreasing cotton was used to cover the coal sample to keep the instrument clean. Then, a vacuum pump was used to vacuum the instrument for $8 \mathrm{~h}$.

(3) Coal sample adsorption: The reference tank was filled with $0.75 \mathrm{MPa}$ methane, which was used as the gas source for coal sample adsorption. This process was repeated until the pressure of the sample tank was maintained at $0.75 \mathrm{MPa}$ for $4 \mathrm{~h}$, at which time the coal sample was considered to achieve adsorption equilibrium.

(4) Measurement of experimental data: Before the gas release, the duration and frequency of the data acquisition were set using software. The solenoid valve between the sample tank and the gauge 
tank was opened using software to begin the gas release process. The data acquisition and experiment cut-off were automatically completed by the software.

\subsection{Experiment for an Outburst Induced by Instant Exposure}

\subsubsection{Materials and Experiment Apparatus}

Briquettes have been widely used in many experiments to reveal the internal mechanism of coal and gas outbursts [30-32]. The experimental results show that a briquette can effectively simulate a destroyed coal seam of high porosity and low intensity [3]. In order to overcome the disadvantages of existing briquettes, such as low intensity, single intensity value, and poor adsorption performance, the briquette used in the experiment was made of coal-like materials that were independently developed [33]. The coal-like material was molded under $15 \mathrm{MPa}$ with pulverized coal of a particle size distribution of $0 \sim 1 \mathrm{~mm}: 1 \sim 3 \mathrm{~mm}=0.76: 0.24$ as aggregate, with a sodium humic acid solution as the cementing agent. The measurement of physical and mechanical properties shows that the intensity of the briquette was $0.5 \sim 2.8 \mathrm{MPa}$, and it could be adjusted by the concentration of the cementing agent, and the physical and mechanical parameters of the briquette were close to those of a Type IV outburst of soft coal [30-32]. The briquettes used in the experiment were made of $C_{13}$ coal.

The outburst experiment was performed with a "coal and gas outburst simulation system" developed on the basis of the CSIRO model [34]. In combination with the above coal-like material, the instrument could realize a quantitative control of the in situ stress, gas pressure and coal intensity, satisfying the experimental study on coal and gas outbursts at different conditions. As shown in Figure 2, the sealed chamber with a length of $600 \mathrm{~mm}$ and an inner diameter of $200 \mathrm{~mm}$ was the main space for loading the briquette and gas adsorption. An inflatable plate with a radial air hole which could ensure a uniform inflation of the coal sample was set at the rear end of the chamber to simulate the real gas boundary conditions. At the same time, with the aid of a microcomputer-controlled hydraulic loading device, the inflatable plate could apply axial pressure on the briquette to simulate different in situ stresses. The front end of the chamber was equipped with a rapid exposure device with an outburst export of $60 \mathrm{~mm}$ in diameter in the middle to simulate coal and gas outbursts induced by instant exposure, e.g., when uncovering rock cross-cut coal. The rapid exposure device can be fully opened within $0.1 \mathrm{~s}$, avoiding the impact of slow release on the outburst. The rapid exposure device and chamber were connected by threads, which is convenient for briquette filling. Three equally spaced gas pressure sensors with a maximum acquisition frequency of $1000 \mathrm{~Hz}$ were arranged on top of the chamber to realize real-time monitoring and acquisition of the instant pressure of the outburst. In addition, the VW-6000 dynamic analysis system made by Keyence was used in the experiment to record the instant outburst moments with the system's high-speed video recording function.

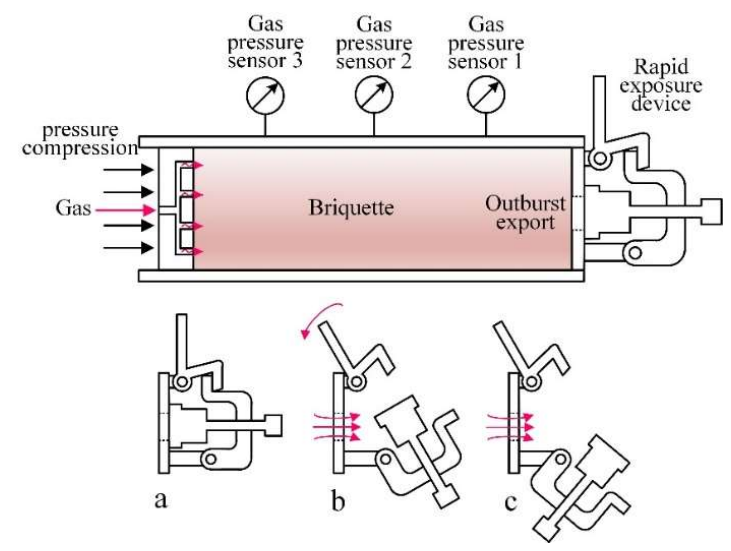

Figure 2. Coal and gas outburst simulation system: (a) initial state; (b) the opening process of the rapid exposure device; (c) the rapid exposure device is completely open. 


\subsubsection{Experiment Method and Procedure}

Although the difference in gas release intensity can be achieved by applying different in situ stresses on the briquette, this can also cause many differences in the degree of coal fragmentation, elasticity, and so forth that would affect the outburst results [12]. In order to ensure that the gas release intensity was the only variable in the experiment, $\mathrm{He}$ (gas 1), $\mathrm{N}_{2}$ (gas 2), $80 \% \mathrm{~N}_{2}+20 \% \mathrm{CO}_{2}$ (gas 3), $70 \% \mathrm{~N}_{2}+30 \% \mathrm{CO}_{2}$ (gas 4), $\mathrm{CH}_{4}$ (gas 5), 30\% $\mathrm{N}_{2}+70 \% \mathrm{CO}_{2}$ (gas 6), and $\mathrm{CO}_{2}$ (gas 7) were selected as the experimental gases. The release intensity of each gas was characterized by the released gas volume within the first second which could be measured with the instruments and methods in Section 2.1, and the results are shown in Table 1.

The briquette with a uniaxial compressive strength of $2.0 \mathrm{MPa}$ was chosen as the experimental coal, and its physical and mechanical properties were as follows: tensile strength $=0.198 \mathrm{MPa}$, modulus of elasticity $=315 \mathrm{MPa}$, Poisson's ratio $=0.35$, apparent density $=1330 \mathrm{~kg} / \mathrm{m}^{3}$, true density $=1470 \mathrm{~kg} / \mathrm{m}^{3}$, porosity $=9.953 \%$, Langmuir volume $V_{L}=21.758 \mathrm{~cm}^{3} / \mathrm{g}$, and Langmuir pressure $p_{L}=1.358 \mathrm{MPa}$.

During mining, the disappearance of the sealing effect of a coal pillar establishes the occurrence conditions for an outburst. Field monitoring data of coal pillar loading suggest that confining pressure in a typical underground coal pillar ranges from 0 to $10 \mathrm{MPa}$ and that the average confining pressure typically is approximately $5 \mathrm{MPa}$. Therefore, the in situ stress was determined to be $5.0 \mathrm{MPa}$ [31]. The gas pressure was determined to be $0.75 \mathrm{MPa}$ which is close to the critical value of gas pressure $(0.74 \mathrm{MPa})$ in the identification of outburst coal seam. The mass, the instantaneous throwing speed and the average particle size of the outburst coal, and outburst duration were selected to reflect the outburst results. These four indexes could reflect the outburst intensity because they are important parameters for calculating the main energy consumption, such as outburst crushing work and throwing work. In the experiment, the mass of outburst coal was obtained by subtracting the mass of the remaining coal from the total mass of the briquette, and the average particle size of the outburst coal was obtained with mathematical statistics using the particle size distribution of the outburst coal, and the instantaneous throwing speed of the outburst coal and outburst duration were obtained through a high-speed video recording.

The main procedure for the instant exposure-induced outburst experiment was as follows: (1) The prepared coal-like material was compressed in the chamber for $30 \mathrm{~min}$ and dried for 5 days to form a briquette. (2) The briquette was vacuumed with a vacuum pump for $24 \mathrm{~h}$ and then inflated with a predetermined pressure gas for $48 \mathrm{~h}$. After that, stress was applied to the briquette. (3) The rapid-exposure device was instantly opened to induce outburst. During the period, a gas pressure collection system and high-speed camera were used for to record information. (4) After the experiment, the results were recorded, e.g., an outburst occurred or did not occur, the shape of outburst holes, and the mass of the outburst pulverized coal. 
Table 1. Results of the outburst experiments and energy calculations.

\begin{tabular}{|c|c|c|c|c|c|c|c|c|}
\hline Gas & $\begin{array}{c}\text { Released Gas } \\
\text { Volume within } \\
1 \mathrm{~s}\left(10^{-3} \mathrm{~m}^{3} / \mathrm{kg}\right)\end{array}$ & $\begin{array}{c}\text { Expansive } \\
\text { Energy of } \\
\text { Released Gas } \\
\text { within } 1 \mathrm{~s}(\mathrm{~J} / \mathrm{kg})\end{array}$ & Outburst Type & $\begin{array}{c}\text { Outburst } \\
\text { Duration (s) }\end{array}$ & $\begin{array}{l}\text { Outburst Coal } \\
\text { Mass (kg) }\end{array}$ & $\begin{array}{l}\text { Instantaneous } \\
\text { Throwing Speed } \\
\text { of the Outburst } \\
\text { Coal }(\mathrm{m} / \mathrm{s})\end{array}$ & $\begin{array}{c}\text { Average } \\
\text { Particle Size of } \\
\text { the Outburst } \\
\text { Coal }(\mathrm{mm})\end{array}$ & $\begin{array}{l}\text { Total Energy } \\
\text { Consumption of } \\
\text { the Outburst (J) }\end{array}$ \\
\hline He (gas 1) & 0 & 0 & A & 0 & 0 & 0 & 0 & 0 \\
\hline $\mathrm{N}_{2}$ (gas 2) & 0.023 & 4.48 & A & 0 & 0 & 0 & 0 & 0 \\
\hline $\begin{array}{l}80 \% \mathrm{~N}_{2}+ \\
20 \% \mathrm{CO}_{2} \\
\text { (gas 3) }\end{array}$ & 0.047 & 9.22 & A & 0 & 0 & 0 & 0 & 0 \\
\hline $\begin{array}{c}70 \% \mathrm{~N}_{2}+ \\
30 \% \mathrm{CO}_{2} \\
\text { (gas } 4)\end{array}$ & 0.057 & 11.12 & B & 0.23 & 0.203 & 2.865 & 2.519 & 7.17 \\
\hline $\mathrm{CH}_{4}$ (gas 5) & 0.074 & 14.74 & $\mathrm{C}$ & 0.64 & 1.410 & 14.935 & 2.395 & 203.58 \\
\hline $\begin{array}{c}30 \% \mathrm{~N}_{2}+ \\
70 \% \mathrm{CO}_{2} \\
\text { (gas 6) }\end{array}$ & 0.099 & 19.40 & $\mathrm{C}$ & 0.71 & 1.479 & 14.957 & 2.094 & 221.68 \\
\hline $\mathrm{CO}_{2}(\operatorname{gas} 7)$ & 0.128 & 25.13 & $\mathrm{C}$ & 0.81 & 1.565 & 14.983 & 1.840 & 242.59 \\
\hline
\end{tabular}




\section{Experimental Results and Discussion}

\subsection{Gas Release Experiment Results and Analysis}

It can be seen from Figure 3 that the released methane volume obviously increases with the increasing stress. The maximum released gas volume (in the failure stage) is about 2.4 times the minimum released gas volume (in the compaction stage) within the same period. In addition, the difference in the amount of released methane caused by stress increases with the increasing release period. The coal samples of $12 \mathrm{MPa}$ and post-peak 2.5 MPa were taken as examples, and the difference in released methane volume between these two stress states and the pre-peak $0 \mathrm{MPa}$ gradually increased with time, as shown in Figure 4. It indicates that the difference in gas release caused by stress has a greater impact on the longer duration outbursts.

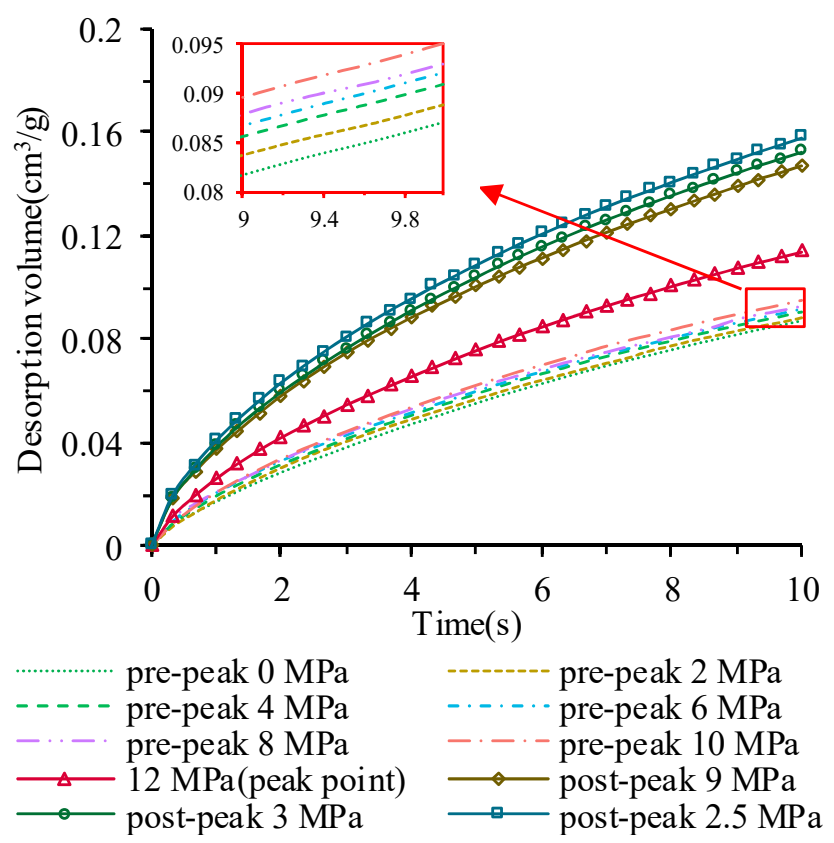

Figure 3. Released methane volume in the coal under different stresses.

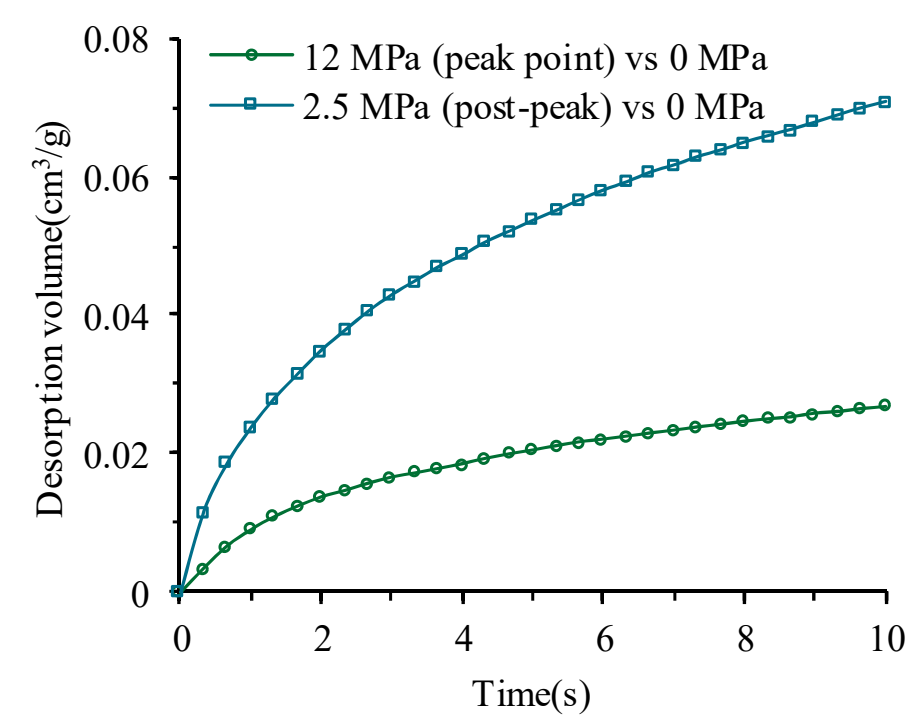

Figure 4. The difference in released methane volume between $12 \mathrm{MPa}$ (peak point), post-peak $2.5 \mathrm{MPa}$ and the pre-peak $0 \mathrm{MPa}$. 
As shown in Figure 5, the methane release under different stress conditions is obviously periodic, and shows different characteristics in the four stages of deformation and failure. The released methane volume was stable in the compaction stage (OA), increased slightly by only $6.1 \%$ in the elastic stage $(A B)$, increased significantly by $27.1 \%$ in the yield stage $(B C)$, and surged by $56.1 \%$ in the failure stage (CD). Yield point $B$ was the abrupt point of gas release in the stress-strain curve. The amount of released methane was stable before point $B$ and increased suddenly after point $B$.

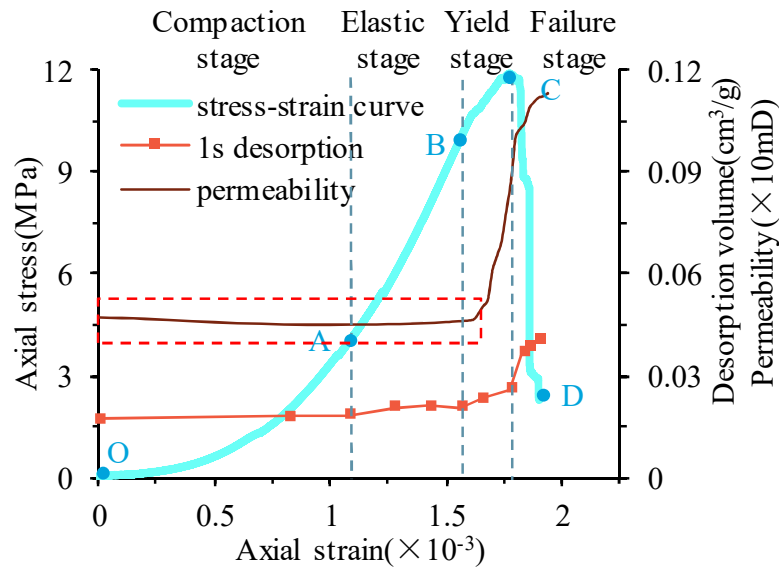

(a)

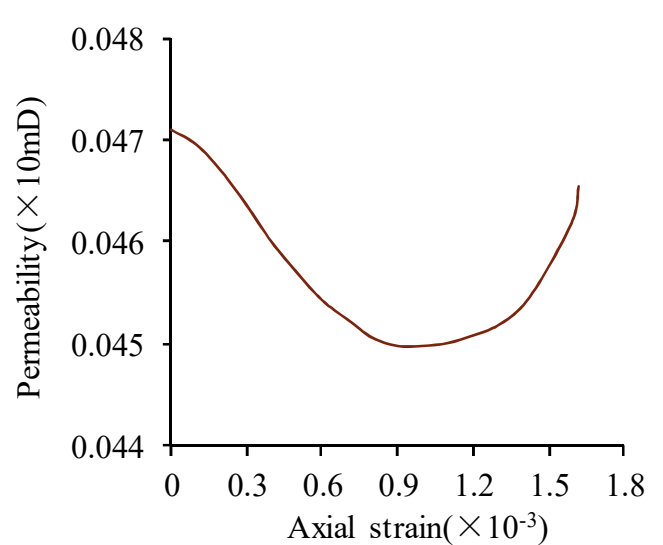

(b)

Figure 5. Released methane volume and permeability of the coal during stress loading. (a) Released methane volume and permeability of the coal in the four stages; (b) permeability of the coal in the compaction and elasticity stages.

Gas release from coal is a complicated process consisting of gas desorption, diffusion in pores and seepage in fissures, etc. With stress loading, the above processes will be affected to varying degrees due to the evolution of pores and fissure structures in the coal $[23,28]$. In this work, with the change in stress, the variation trend in the released methane volume and permeability that can quantify the gas transport capacity in coal is consistent as shown in Figure 5; and the correlation coefficient is 0.974 , indicating that the change in the gas seepage channel in the coal is the main reason for the change in methane release. It should be noted that the permeability in Figure 5 was calculated by the body strain with Equation (5) which has been proven to be accurate in calculations of coal permeability $[35,36]$. And the permeability in Figure $5 \mathrm{~b}$ decreases slowly in the compaction stage due to the effect of compaction and increases slowly in the elastic stage, which is consistent with the conclusions of Duan [36].

$$
k=k_{0}\left(\frac{\left(\varphi_{0}-\varepsilon_{v}+\sigma_{0} / K\right)}{\varphi\left(1-\varepsilon_{v}\right)}\right)^{3},
$$

where $k$ is permeability, $k_{0}$ is the initial permeability, $\varphi$ is porosity, $\varphi_{0}$ is the initial porosity, $\varepsilon_{v}$ is the volumetric strain, $\sigma_{0}$ is hydrostatic pressure, and $K$ is the frame bulk modulus.

Therefore, the variation in methane release in coal during stress loading can be explained with the evolution of fractures in the coal sample. In the compaction and elasticity stages, the fracture in the coal develops slowly, and the gas seepage channel is basically unchanged, which has little effect on methane release. In the yield stage, after the coal exceeds the yield limit, it transforms from elastic deformation to plastic deformation, qualitative changes take place in the micro fractures, and enormous shear fractures occur and connect to form a penetrating fissure, which increases the gas seepage channel with the accordingly increasing methane release quantity. In the failure stage, after the specimen passes the stress peak, its internal structure is destroyed, the fractures accelerate and form a macro fracture surface, so the released methane volume in this stage changes dramatically. Finally, when the coal rock achieves residual strength, the permeability reaches the limit value, and so does the corresponding methane release capacity. 


\subsection{Outburst Experiment Results and Analysis}

\subsubsection{Outburst Experimental Phenomena}

Based on the cast distance and particle separation appearance of the scattered pulverized coal, Jiang divided the outburst results into three types: strong outburst (C-type), weak outburst (B-type), and no outburst (A-type): In C-type, the pulverized coal was cast to a greater distance of 5 6 $\mathrm{m}$ with apparent separation of the scattered pulverized coal; in B-type, the pulverized coal was cast to a distance of less than $2 \mathrm{~m}$ with no particle separation found; in A-type, only a small amount of flow was found when opening the rapid exposure device $[5,26]$. The outburst results in this work were divided into three types by the above indicators, as shown in Table 1 . And new characteristics were discovered to clearly identify the outburst types. In a C-type outburst experiment (Figure 6a), a large amount of coal powder and gas gushed out, and the outburst hole indicated a form that was obviously small in the mouth and large in the chamber, which is very similar to a true outburst. The ejection speed of the mixed fluid was about 10 15 m/s, and the duration was $0.3 \sim 1 \mathrm{~s}$. In the B-type outburst experiment (Figure 6b), only a small amount of coal powder and gas gushed out, and the outburst hole was large in the mouth and small in the chamber. The ejection speed of the mixed fluid was about 2 5 m/s, and the duration of the outburst about $0.2 \mathrm{~s}$. In the A-type outburst experiment (Figure $6 \mathrm{c}$ ), the weak gas, leaked at the moment of exposure, can be heard with no coal powder gushing out. The pressure dropped to atmospheric pressure for dozens of seconds at the rate of $0.01 \sim 0.02 \mathrm{MPa} / \mathrm{s}$ which is far less than the drop rate of the A and B-type outbursts.

The experimental results show that the risk and intensity of an outburst will increase with an increasing gas release intensity. As shown in Table 1, the outburst does not occur in the experiments carried out with gas 1 , gas 2 , and gas 3 with low release intensity, but in the experiments carried out with gas 4, gas 5, gas 6, and gas 7 with high release intensity. Besides, the mass of the outburst coal, outburst duration, and instantaneous throwing speed of the coal powder used to characterize the outburst intensity all increase with the gas release intensity.

As shown in Table 1, the particle size of the pulverized coal decreased with the increase in gas release intensity. It indicates that gas pressure relief has a destructive effect on the coal, which is consistent with the conclusions of Lama and Bodziony [37] and Wang et al. [38], and also indicates that the higher the gas release intensity, the stronger the damage to the coal.

In the C-type and B-type outburst process, the pressure in the area where the outburst hole did not reach still decreased in varying degrees. The experiments with gas 7 (C-type) and gas 4 (B-type) were taken as examples. In the experiment with gas 7 , the gas pressure at the No. 1 sensor reached by the outburst hole instantly dropped to atmospheric pressure, while the gas pressure at the No. 2 and No. 3 sensors that the outburst hole did not reach dropped slowly, and fell to atmospheric pressure at the end of the outburst (Figure 6a). In the experiment with gas 4 (B-type), the gas pressure at the No. 1 sensor reached by the outburst hole instantly dropped to atmospheric pressure, while the gas pressure at the No. 2 and No. 3 sensors that the outburst hole did not reach dropped very slowly, and only to $0.65 \mathrm{MPa}$ at the end of the outburst (Figure 6b). This phenomenon indicates that the coal around the outburst hole that did not blowout also released gas in the outburst process. This explains why the measured amount of gas emitted from outburst coal far exceeds its gas content. Therefore, when analyzing the internal energy of the gas, it is not enough to only consider the throwing coal, all the coal affected by the outburst should be studied. At the same time, the above phenomenon also shows that the gas release from the coal surrounding the outburst hole increases with the outburst intensity. 


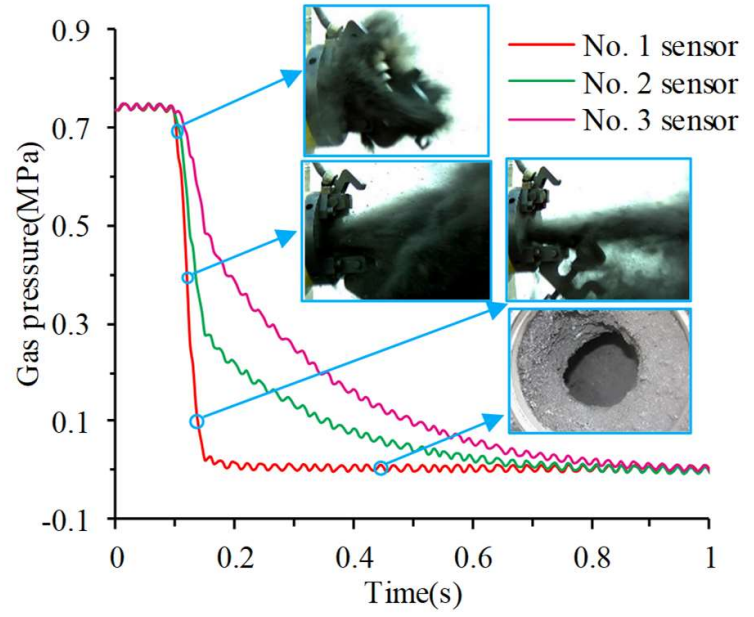

(a)

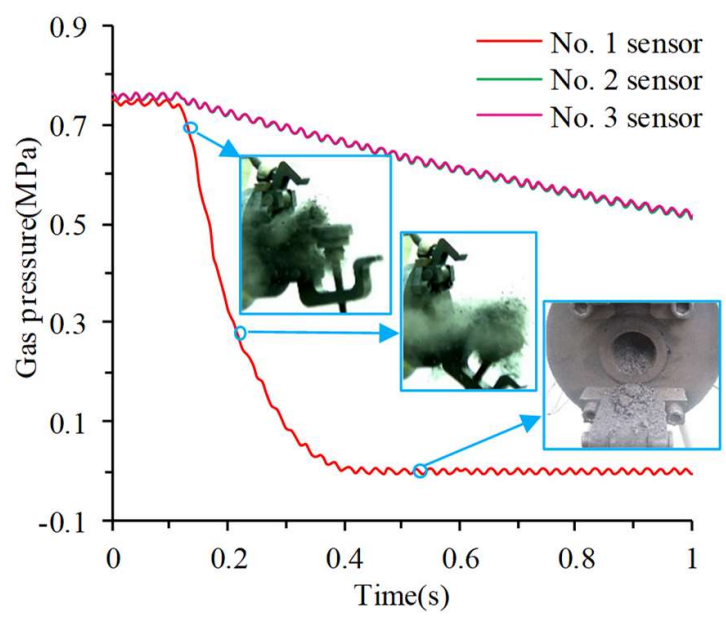

(b)

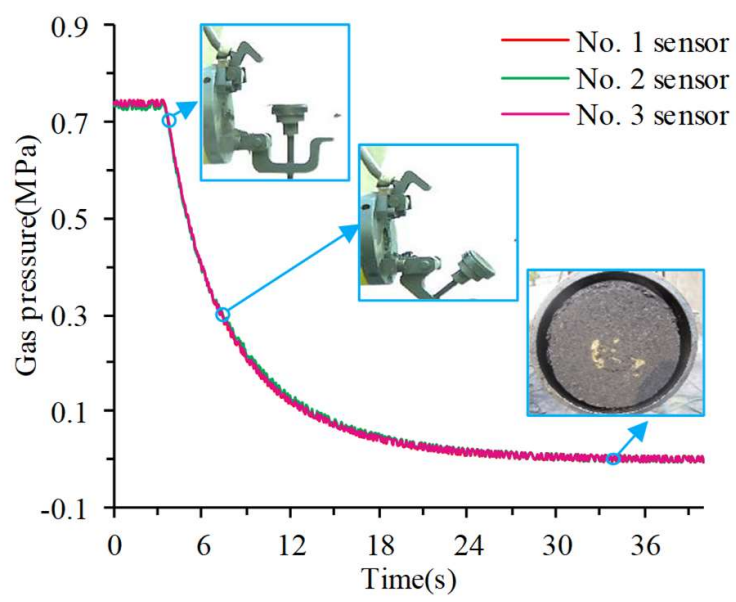

(c)

Figure 6. Gas pressure and corresponding experimental phenomena in the outburst process: (a) Outburst experiment with $\mathrm{CO}_{2}$ (gas 7); (b) Outburst experiment with $70 \% \mathrm{~N}_{2}+30 \% \mathrm{CO}_{2}$ (gas 4);

(c) Outburst experiment with $\mathrm{N}_{2}$ (gas 2).

\subsubsection{Energy Analysis of the Outburst Experiments}

Compared with the phenomena analysis, the energy analysis is more comprehensive and scientific to quantify the outburst results [28]. Therefore, the effect of gas desorption intensity on outburst was quantified from an energy perspective. The gas release intensity was characterized by the expansive energy of released gas within $1 \mathrm{~s}$ calculated by Equation (6), and the outburst intensity was characterized by the total energy consumption calculated by Equation (7). The results are shown in Table 1. It should be noted that Equations (6) and (7) are applied widely in outburst energy calculations [39].

$$
W=\frac{p_{2} V}{n-1}\left[\left(\frac{p_{1}}{p_{2}}\right)^{\frac{n-1}{n}}-1\right],
$$

where $W$ is the gas expansion energy, $p_{1}$ is the pre-outburst gas pressure; $p_{2}$ is the post-outburst gas pressure, $V$ is the gas volume involved in the outburst in the $p_{2}$ state, and $n$ is the gas adiabatic index.

$$
A=\frac{6 \alpha}{\rho}\left[\frac{1}{d}-\frac{1}{D}\right]+\frac{1}{2} v^{2},
$$


where $A$ is the total energy consumption of the outburst, $\alpha$ is crushing specific work, $\rho$ is the apparent density of the crushed coal, $D$ and $d$ are the average diameters of the pre-outburst and post-outburst coal, and $v$ is the instantaneous throwing speed of the outburst coal.

The energy calculation shows that the increased gas release intensity increases the outburst risk and intensity, which is consistent with Section 3.2.1. Based on Table 1, it can be found that small differences in the expansive energy of released gas within $1 \mathrm{~s}$ may lead to huge differences in outburst energy consumption. Take gas 4 and gas 5 as examples, the gas release intensity difference between the two was only $3.62 \mathrm{~J} / \mathrm{kg}$, but the total outburst energy consumption difference between the two was $196.41 \mathrm{~J}$. This indicates that the intensity of gas release is the sensitive physical quantity that influences the outburst.

Yang et al. [5] and Jiang et al. [26] believe that an outburst will occur when the potential energy in coal reaches a given value. For this experiment, there is also a critical value for the expansive energy of released gas since it is the only difference in the coal potential energy. From the energy calculation in Table 1, it can be found that the critical value is about $11.12 \mathrm{~J} / \mathrm{kg}$, no outburst occurred for the experiments with gas release intensity lower than the critical value, and outbursts occurred for experiments with a gas release intensity higher than the critical value. The value provides a reference for outburst prediction.

Based on the above analysis, the effect of the gas release intensity on outburst intensity can be understood in terms of energy. (1) The higher gas release intensity means that more released gas participates in the outburst under the same condition, and the outburst intensity increases accordingly. (2) Gas pressure relief has a destructive effect on coal, as a higher gas release intensity can induce a larger outburst area (i.e., outburst coal mass) due to the greater destructive power, which in turn increases the gas release from the surrounding coal and outburst coal, resulting in a longer outburst duration. At the same time, the extension of the outburst duration could in turn increase the amounts of gas release. The above-mentioned chain reaction eventually leads to an increase in the total energy consumption (i.e., the outburst intensity).

\subsection{Discussion}

In this outburst experiment, by assuming that the release intensity of gas 3 represents the original coal release intensity, the release intensity of gas 4 , gas 5 , and gas 6 may respectively represent the release intensity of coal in the elastic stage, yield stage and failure stage based on quantification of gas release intensity growth caused by stress growth in Section 3.1. Then the results of the outburst experiments can be understood as follows: there is no outburst occurrence for original coal, and there is a weak outburst occurrence in the elastic stage and a strong outburst occurrence in the yield stage and failure stage. This indicates that the difference in gas release in coal with different stresses will result in differences in the outburst results. In other words, the influence of the in situ stress on the gas release intensity in coal is one of the important reasons for stress-induced outbursts. It also indicates that gas release intensity during stress changes in coal can be taken as an important monitoring indicator in the prevention and control of outbursts.

The difficulty in prediction of coal and gas outbursts lies in their abruptness. In this experiment, during the yield and failure stages of the stress-strain curve, the cracks in the coal sample were rapidly opened, developed, intersected and interconnected to form macroscopic fracture surfaces, the release intensity of gas rose sharply, the outburst potential energy changed abruptly, which had a great influence on outburst occurrence. Therefore, the yield and failure stages of coal can be used as the main detection stages for outburst prevention.

Although some differences exist between the on-site stress state and the uniaxial compression state, a certain similarity exists in gas migration characteristics. The tests on the gas release law in coal in this article provide reference for studying the characteristics of gas emission in practical conditions. 


\section{Conclusions}

1. The influence of in situ stress on gas release intensity was explored and quantified in gas release experiments for coal under different axial stresses. The experimental result shows that with the increase in the coal stress, the released methane volume increased by 1 2.4 times and showed an obvious periodicity, which was basically unchanged in the compaction stage, increased slightly in the elastic stage, increased significantly in the yield stage, and surged in the failure stage.

2. The change in the gas seepage channel was proved to be the main reason for the change in methane release in coal under different stress conditions.

3. The influence of the gas release intensity on outbursts was investigated through exposure-induced outburst experiments of different gases, and quantified through the energy analysis on the outburst experiments. The experimental result shows that the increase in gas release intensity will increase the outburst risk and intensity. The energy analysis shows that small differences in gas release intensity could lead to huge differences in outburst intensity. It indicated that the gas release intensity is a sensitive physical quantity that influences the outbursts.

4. The influence of in situ stress on the gas release intensity in coal was proved to be one of the important reasons for stress-induced outburst based on the comprehensive analysis of the two experiments. It enriches the impact mechanism of in situ stress on outbursts, and indicates that gas release intensity during stress changes in coal can be taken as an important monitoring indicator in the prevention and control of outbursts.

Author Contributions: H.W. and L.Y. proposed the topic of this study; H.W. and B.Z. designed the experiment; B.Z., G.Y. and W.W. performed the experiment; H.W. and B.Z. analyzed the data and wrote the final manuscript.

Funding: This research received no external funding.

Acknowledgments: This research was funded by the National Natural Science Foundation of China (51427804, 41672281), Natural Foundation of Shandong Province (ZR2017MEE023), Huainan science and technology project (2016A02).

Conflicts of Interest: The authors declare no conflict of interest.

\section{References}

1. Nie, B.; Li, X. Mechanism research on coal and gas outburst during vibration blasting. Saf. Sci. 2012, 50, 741-744. [CrossRef]

2. Li, H.; Feng, Z.; Zhao, D.; Duan, D. Simulation experiment and acoustic emission study on coal and gas outburst. Rock Mech. Rock Eng. 2017, 50, 2193-2205. [CrossRef]

3. Cao, Y.; He, D.; Glick, D.C. Coal and gas outbursts in footwalls of reverse faults. Int. J. Coal Geol. 2001, 48, 47-63. [CrossRef]

4. Huang, W.; Chen, Z.; Yue, J.; Zhang, Y.; Yang, M. Failure modes of coal containing gas and mechanism of gas outbursts. Min. Sci. Technol. 2010, 20, 504-509. [CrossRef]

5. Yang, D.; Chen, Y.; Tang, J.; Li, X.; Jiang, C.; Wang, C.; Zhang, C. Experimental research into the relationship between initial gas release and coal-gas outbursts. J. Nat. Gas Sci. Eng. 2018, 50, 157-165. [CrossRef]

6. Han, J.; Zhang, H.W.; Li, S.; Song, W.H. The characteristic of in situ stress in outburst area of China. Saf. Sci. 2012, 50, 878-884. [CrossRef]

7. Xie, H.; Xie, J.; Gao, M.; Zhang, R.; Zhou, H.; Gao, F.; Zhang, Z. Theoretical and experimental validation of mining-enhanced permeability for simultaneous exploitation of coal and gas. Environ. Earth Sci. 2015, 73, 5951-5962. [CrossRef]

8. Chen, Z.Y.; Xiao, Z.X.; Zou, M. Research on mechanism of quantity discharge of firedamp from coal drift of headwork surface reflect coal and gas outburst. Int. J. Hydrogen Energy 2017, 42, 19395-19401. [CrossRef]

9. Zhou, Z.; Li, X.; Zou, Y.; Jiang, Y.; Li, G. Dynamic brazilian tests of granite under coupled static and dynamic loads. Rock Mech. Rock Eng. 2014, 47, 495-505. [CrossRef] 
10. Liu, H.; Cheng, Y. The elimination of coal and gas outburst disasters by long distance lower protective seam mining combined with stress-relief gas extraction in the Huaibei coal mine area. J. Nat. Gas Sci. Eng. 2015, 27, 346-353. [CrossRef]

11. Beamish, B.B.; Crosdale, P.J. Instantaneous outbursts in underground coal mines: An overview and association with coal type. Int. J. Coal Geol. 1998, 35, 27-55. [CrossRef]

12. Zhang, L.; Xu, J.; Lu, Q. Experimental study on the effect of ground stress on coal and gas outburst. Disaster Adv. 2012, 5, 17-23.

13. Zhao, H.B.; Yin, G.Z. Study on impact of coal and gas outburst Strength caused by principal stress. Disaster Adv. 2010, 3, 388-391.

14. Yang, W.; Lin, B.; Zhai, C.; Li, X.; An, S. How in situ stresses and the driving cycle footage affect the gas outburst risk of driving coal mine roadway. Tunn. Undergr. Space Technol. 2012, 31, 139-148. [CrossRef]

15. Yang, W.; Lin, B.; Xu, J. Gas outburst affected by original rock stress direction. Nat. Hazards 2014, 72, 1063-1074. [CrossRef]

16. An, F.; Cheng, Y. The Effect of a tectonic stress field on coal and gas outbursts. Sci. World J. $2014,2014$. [CrossRef] [PubMed]

17. Gao, K.; Liu, Z.G.; Jian, L. Effect of geostress on coal and gas outburst in the uncovering tectonic soft coal by cross-cut. Chin. J. Rock Mech. Eng. 2015, 34, 305-312.

18. Liu, Q.; Wang, E.; Kong, X.; Li, Q.; Hu, S.; Li, D. Numerical simulation on the coupling law of stress and gas pressure in the uncovering tectonic coal by cross-cut. Int. J. Rock Mech. Min. Sci. 2018, 103, 33-42. [CrossRef]

19. Cheng, Y.P.; Zhang, X.L.; Liang, W. Controlling effect of ground stress on gas pressure and outburst disaster. J. Min. Saf. Eng. 2013, 30, 408-414.

20. Li, H. Major and minor structural features of a bedding shear zone along a coal seam and related gas outburst, Pingdingshan coalfield, Northern China. Int. J. Coal Geol. 2001, 47, 101-113. [CrossRef]

21. Li, H.; Ogawa, Y.; Shimada, S. Mechanism of methane flow through sheared coals and its role on methane recovery. Fuel 2003, 82, 1271-1279. [CrossRef]

22. Jasinge, D.; Ranjith, P.G.; Choi, S.K. Effects of effective stress changes on permeability of latrobe valley brown coal. Fuel 2011, 90, 1292-1300. [CrossRef]

23. He, M.C.; Wang, C.G.; Feng, J.L.; Li, D.J.; Zhang, G.Y. Experimental investigations on gas desorption and transport in stressed coal under isothermal conditions. Int. J. Coal Geol. 2010, 83, 377-386. [CrossRef]

24. Xu, X.; Sarmadivaleh, M.; Li, C.; Xie, B.; Iglauer, S. Experimental study on physical structure properties and anisotropic cleat permeability estimation on coal cores from China. J. Nat. Gas Sci. Eng. 2016, 35, 131-143. [CrossRef]

25. Zhang, C.; Liu, X.; Xu, G.; Wang, X. Effects of loading rate on gas seepage and temperature in coal and its potential for coal-gas disaster early-warning. Energies 2017, 10. [CrossRef]

26. Jiang, C.; Xu, L.; Li, X.; Tang, J.; Chen, Y.; Tian, S.; Liu, H. Identification model and indicator of outburst-prone coal seams. Rock Mech. Rock Eng. 2014, 48, 409-415. [CrossRef]

27. Sobczyk, J. A comparison of the influence of adsorbed gases on gas stresses leading to coal and gas outburst. Fuel 2014, 115, 288-294. [CrossRef]

28. Xu, L.; Jiang, C. Initial desorption characterization of methane and carbon dioxide in coal and its influence on coal and gas outburst risk. Fuel 2017, 203, 700-706. [CrossRef]

29. Charrière, D.; Pokryszka, Z.; Behra, P. Effect of pressure and temperature on diffusion of CO2 and CH4 into coal from the Lorraine basin (France). Int. J. Coal Geol. 2010, 81, 373-380. [CrossRef]

30. Hu, Q.; Zhang, S.; Wen, G.; Dai, L.; Wang, B. Coal-like material for coal and gas outburst simulation tests. Int. J. Rock Mech. Min. Sci. 2015, 74, 151-156. [CrossRef]

31. Tu, Q.; Cheng, Y.; Guo, P.; Jiang, J.; Wang, L.; Zhang, R. Experimental study of coal and gas outbursts related to gas-enriched areas. Rock Mech. Rock Eng. 2016, 49, 3769-3781. [CrossRef]

32. Yin, G.; Jiang, C.; Wang, J.G.; Xu, J.; Zhang, D.; Huang, G. A new experimental apparatus for coal and gas outburst simulation. Rock Mech. Rock Eng. 2016, 49, 2005-2013. [CrossRef]

33. Wang, H.; Zhang, Q.; Yuan, L.; Xue, J.; Li, Q.; Zhou, W.; Li, J.M.; Zhang, B. Development of a similar material for methane-bearing coal and its application to outburst experiment. Rock Soil Mech. 2015, 36, 1676-1682.

34. Wang, H.; Zhang, Q.; Liang, Y.; Xue, J.; Li, Q.; Zhang, B. Coal and gas outburst simulation system based on CSIRO model. Chin. J. Rock Mech. Eng. 2013, 34, 2301-2308. 
35. Palmer, I. Permeability changes in coal: analytical modeling. Int. J. Coal Geol. 2009, 77, 119-126. [CrossRef]

36. Duan, P.; Wang, Z. Experimental research on variations of permeability and porosity for coals. Chin. J. Undergr. Space Eng. 2013, 9, 1283-1288.

37. Lama, R.D.; Bodziony, J. Management of outburst in underground coal mines. Int. J. Coal Geol. 1998, 35, 83-115. [CrossRef]

38. Wang, S.; Elsworth, D.; Liu, J. Rapid decompression and desorption induced energetic failure in coal. J. Rock Mech. Geotech. Eng. 2015, 7, 345-350. [CrossRef]

39. Hu, Q.; Wen, G. Study on the Mechanical Mechanism of Coal and Gas Outburst, 1st ed.; Science Press: Beijing, China, 2013; pp. 286-319. ISBN 978-7-03-036261-2.

2018 by the authors. Licensee MDPI, Basel, Switzerland. This article is an open access article distributed under the terms and conditions of the Creative Commons Attribution (CC BY) license (http://creativecommons.org/licenses/by/4.0/). 